\title{
First description of Echinococcus ortleppi infection in China
}

\author{
Yunliang Shi ${ }^{1}$, Xiaoling Wan ${ }^{1}$, Ziyue Wang ${ }^{2}$, Jun Li ${ }^{1}$, Zhihua Jiang ${ }^{1}$ and Yichao Yang ${ }^{1 *}$
}

\begin{abstract}
Background: Echinococcosis has led to considerable social and economic losses in China, particularly in the endemic communities of the eastern Tibetan Plateau. In China, human cases of Echinococcus granulosus (sensu stricto), E. canadensis and E. multilocularis infections have been described, but no E. ortleppi (G5) infections in humans or animals have been reported.

Results: A case of E. ortleppi infection in a human from Guangxi, which is a non-endemic echinococcosis area in China, is described. A $17 \times 12 \times 20 \mathrm{~cm}$ (diameter) cyst was observed in the liver of the patient, and Echinococcus larvae were collected from the cyst. A morphological examination indicated that the larvae were E. ortleppi, and amplification and analysis of the nicotinamide adenine dinucleotide hydrogenase dehydrogenase subunit 1 (nad1) and cytochrome c oxidase subunit 1 (cox1) genes showed that the larvae had 99-100\% homology with the corresponding E. ortleppi sequences on GenBank.
\end{abstract}

Conclusions: To our knowledge, this report describes the first identification of a human E. ortleppi infection in China. Our data broaden the geographical distribution of this rarely reported species of Echinococcus.

Keywords: Echinococcus ortleppi, Hydatid, Human, China

\section{Background}

Cystic echinococcosis is a globally distributed zoonotic disease caused by the larval form (metacestode) of the dog tapeworm genus Echinococcus (Cestoda: Taeniidae). Humans become infected through the ingestion of Echinococcus spp. eggs that have been deposited from the faeces of the definitive hosts (canids), and the larval stage develops in the viscera of humans [1]. Nine valid species of the genus Echinococcus: E. granulosus (sensu stricto) [G1 (sheep strain), G2 (Tasmanian sheep strain) and G3 (buffalo strain)]; E. equinus (G4); E. ortleppi (G5); $E$. canadensis (G6-G10); E. vogeli; E. felidis; E. oligarthrus; E. multilocularis; and E. shiquicus, have been identified [2-5]. The first five species have often been grouped under the common name E. granulosus (sensu lato). Echinococcus granulosus (s.s.) and E. multilocularis are the

\footnotetext{
*Correspondence: 531174868@qq.com

${ }^{1}$ Institute of Parasitic Disease Prevention and Control, Guangxi Zhuang Autonomous Region Center for Disease Control and Prevention, Nanning 530028, China

Full list of author information is available at the end of the article
}

two most important species responsible for human cystic echinococcosis and alveolar echinococcosis.

Echinococcus ortleppi was formerly known as the cattle strain of E. granulosus (s.l.) or genotype G5 [6, 7], and its morphology and developmental features show substantial differences compared with those of E. granulosus (s.s.) and other taxa. In addition to cattle, buffaloes, camels, sheep, pigs, goats, monkeys and deer can also be infected with E. ortleppi [8-12]. In recent years, several cases of E. ortleppi infection have been reported in Europe, South America, Africa and Asia [13]. Humans acquire the infection and become aberrant intermediate hosts through the accidental ingestion of parasite eggs and metacestodes develop in the liver or lungs.

Four species in the genus Echinococcus have been reported in China: E. granulosus (s.s.); E. canadensis; E. multilocularis; and E. shiquicus [14-19]. Echinococcus granulosus (s.l.) and E. multilocularis are the two common species, and infection with these species can lead to death if left untreated. Two E. canadensis (G7 and G10) human infection cases have been identified in Heilongjiang Province $[17,18]$, and E. shiquicus was isolated from 
a Tibetan fox in Shiqu County in the Qinghai-Tibet Plateau in 2005 [19]. To date, five genotypes of E. granulosus (s.l.), i.e. G1, G3, G6, G7 and G10, have been reported in China [14-18]. All five genotypes can infect humans, and the G1 and G6 genotypes can infect animals; however, the G1 genotype is predominant. Here, we report an E. ortleppi case in a human from Guangxi, South China, that was free of local hydatid infection.

\section{Methods \\ Case presentation}

The 65-year-old male described in this report was residing in Rongshui County, Liuzhou City, Guangxi Province, Southern China. At the time of study he was a teacher, was living in his place of birth, had never left the country prior to diagnosis and had not travelled to any echinococcosis- or schistosomiasis-endemic areas. In May 2017, he felt pain in the right upper abdomen; this pain was persistent and not accompanied by any paroxysmal aggravation, and all other clinical signs were not significant. He did not present with a fever, cough or other symptoms. He visited the People's Hospital of Miao Autonomous County in Rongshui County, and his clinical diagnosis and abdominal ultrasonography indicated a "hepatic cyst".

\section{Morphological and molecular identification}

The surgery was conducted laparoscopically, and Echinococcus was found in and collected from the fluid-filled cyst in the liver. The morphology of the collected Echinococcus was assessed. The total DNA of the Echinococcus parasite was extracted using a commercial DNeasy ${ }^{\circledR}$ Blood \& Tissue Kit (Qiagen, Hilden, Germany) in accordance with the manufacturer's instructions. Two mitochondrial genes, cytochrome $c$ oxidase subunit 1 ( $\operatorname{cox} 1)$ and nicotinamide dehydrogenase subunit 1 (nad1), were amplified using the primers F/COI (5'-TTG AAT TTG CCA CGT TTG AA TGC-3') and R/COI (5'-GAA CCT AAC GAC ATA ACA TAA TGA-3') [20], and JB11 (5'AGA TTC GTA AGG GGC CTA ATA-3') and JB12 (5'ACCACTAACTAATTCACTTTC-3') [21], respectively. The PCRs were performed in a reaction volume of $25 \mu \mathrm{l}$ containing $4 \mu \mathrm{l}$ of DNA, $12.5 \mu \mathrm{l}$ of PCR mix (Takara, Dalian, China), $1 \mu \mathrm{l}$ of each primer $(10 \mathrm{pmol} / \mu \mathrm{l})$ and $6.5 \mu \mathrm{l}$ of PCR-grade water. The amplification consisted of $94{ }^{\circ} \mathrm{C}$ for $3 \mathrm{~min}$ followed by 35 cycles of denaturation at $94{ }^{\circ} \mathrm{C}$ for $1 \mathrm{~min}$, annealing at $50{ }^{\circ} \mathrm{C}(\operatorname{cox} 1) / 54{ }^{\circ} \mathrm{C}$ (nad 1$)$ for $1 \mathrm{~min}$ and extension at $72{ }^{\circ} \mathrm{C}$ for $1 \mathrm{~min}$, and a final extension step at $72{ }^{\circ} \mathrm{C}$ for $10 \mathrm{~min}$. The PCR products were analysed by electrophoresis in 1.5\% agarose gels. The amplified DNA was purified from the gel using an Agarose Gel DNA Extraction Kit (Takara), cloned into a
PMD-19T vector (Takara) and transformed and propagated into DH5 $\alpha$-competent $E$. coli (Takara).

The $\mathrm{T}$ plasmid vector-conserved primer M13 was used to select the positive clones, and the plasmid DNA was isolated from single colonies using a MiniBEST Plasmid Purification Kit (Takara). The recombinant plasmids were sequenced at Sangon Biotech (Shanghai, China). The sequences were compared with those available in the GenBank database using the Basic Local Alignment Search Tool (BLASTn; http://blast.ncbi.nlm.nih.gov/ Blast.cgi). The phylogenetic trees of the nad 1 and cox 1 gene sequences of E. ortleppi China and other related strains were constructed using the maximum likelihood (ML) method with MEGA v.7.0 [22].

\section{Results}

Abdominal ultrasonography showed cystic-like low-density shadows in the right lobe of the liver; the boundary was clear, and the size of the shadow was approximately $17 \times 12 \times 20 \mathrm{~cm}$ (Fig. 1). No dilatation of the intrahepatic and extrahepatic bile ducts was observed, and no abnormal tissue was detected in the hilum of the liver. The size and shape of the gall-bladder and spleen were normal. According to the WHO ultrasound image classification guidelines [23], the CE type belongs to CE1-large (CE11). A laparoscopic examination revealed compensatory enlargement of the left lobe of the liver, enlargement of the right lobe of the liver and morphological abnormalities. The cystic mass was approximately $17 \times 12 \times 20 \mathrm{~cm}$ in size and exhibited a clear cystic fluid, calcification of the cyst wall, and a layer of translucent white powdery material with a thickness of approximately $0.2-0.3 \mathrm{~cm}$ in the cyst. The cyst (cystic echinococcosis) contained many protoscoleces, each of which had many hooks (Fig. 2a-c).

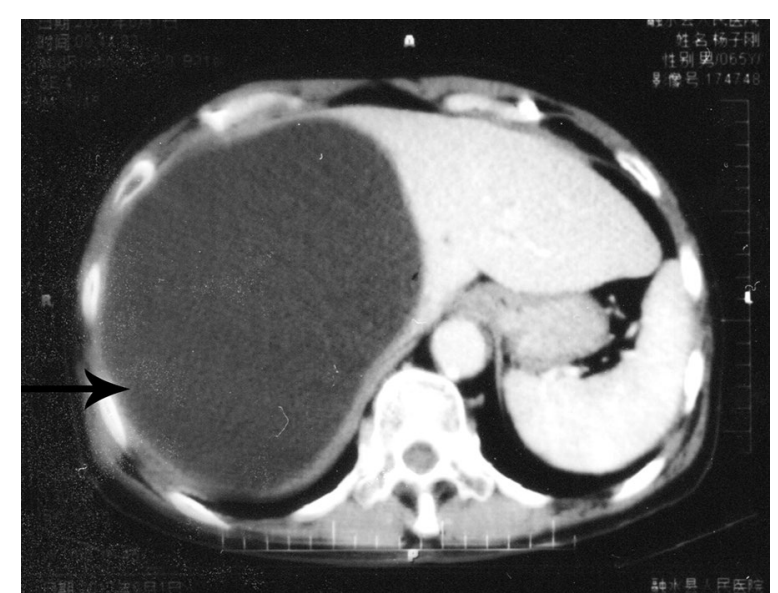

Fig. 1 Abdominal ultrasonography detected a hydatid cyst (arrow) with a size of $17 \times 12 \times 20 \mathrm{~cm}$ (diameter) in the liver of the patient 


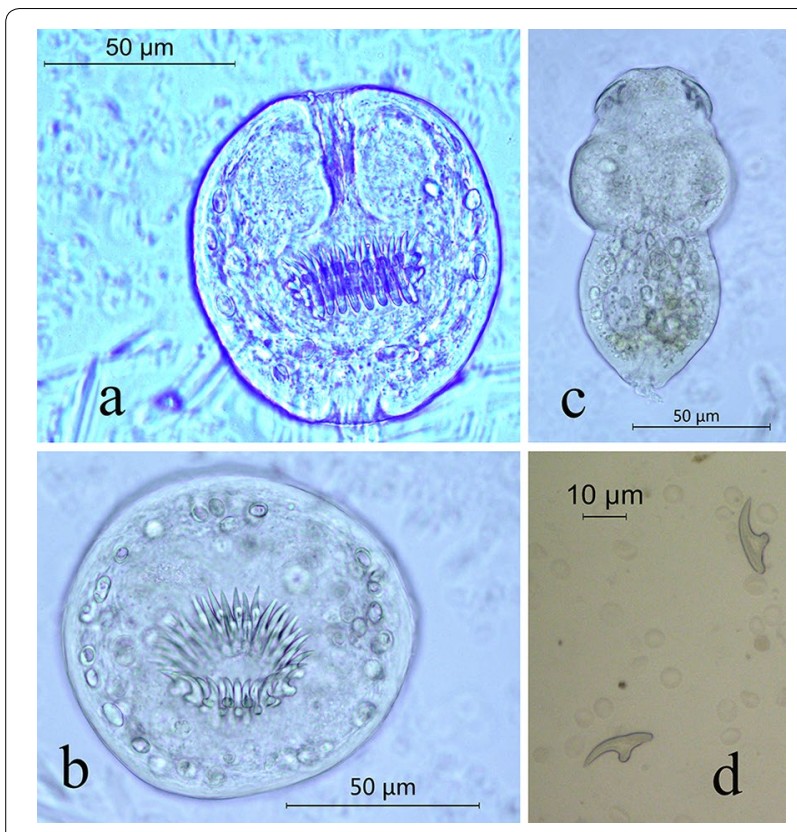

Fig. 2 Protoscoleces and hooklets of Echinococcus ortleppi. a Invaginated scolices observed by microscopy (40x). b Evaginated scolices $(40 x)$. c Evaginated scolices of the protoscolices $(40 x)$. $\mathbf{d}$ Hooks of the larvae $(40 x)$

Each protoscolex appeared as a spherical body with a diameter of approximately $95 \times 80 \mu \mathrm{m}$ and an invaginated scolex with 30 hooks (Fig. 2b), and each hook was $20 \mu \mathrm{m}$ (Fig. 2d).

A 935-bp nucleotide sequence for cox 1 loci and a 530-bp sequence for nad 1 loci were obtained through sequencing. The $\operatorname{cox} 1$ and nad 1 sequences were submitted to the GenBank database under the accession numbers MN058591 and MN058592, respectively. The BLAST analysis showed that the cox 1 sequence exhibited $99-100 \%$ homology with that of E. ortleppi in GenBank isolates previously collected in France (GenBank:
KU743919, KU743922 and KU743922), Estonia (GenBank: KY766908, KY766906 and KY766907), Japan (GenBank: AB235846), Africa (e.g. GenBank: KU842045) and the UK (GenBank: KU378107). The nad 1 sequences showed $99-100 \%$ homology to the E. ortleppi sequences in GenBank obtained from Estonia (GenBank: KY766908 and KY766907) and Sudan (GenBank: KU842045). Both cox 1 and nad 1 sequences showed only $93-94 \%$ homology to those of $E$. granulosus. The phylogenetic tree of $E$. ortleppi and other related strains derived from part of the cox 1 and nad 1 genes showed that the E. ortleppi strain collected in China belongs to the same group as the strains of E. ortleppi in GenBank (Additional file 1: Figure S1 and Additional file 2: Figure S2, respectively).

Echinococcus ortleppi-infected serum was detected using an ELISA kit (Combined Biotech Co. Ltd., Shenzhen, China) that could detect a wide range of Echinococcus [including E. granulosus (s.s.) and E. multilocularis] IgG antibodies and showed positive reactivity with $E$. ortleppi. To determine whether the animals and humans in the patient's residential area were infected with $E$. ortleppi, 10 dog faeces samples were collected and examined using the Kato-Katz technique. Forty human serum samples from families, neighbours and colleagues of patients were collected and analysed using an ELISA kit (Combined Biotech Co. Ltd., Shenzhen, China) to detect Echinococcus IgG antibodies. No positive samples were detected from dogs or humans.

\section{Discussion}

Echinococcus ortleppi is a cattle strain (genotype G5) of E. granulosus that is mainly transmitted between dogs and cattle, and humans become infected through the accidental ingestion of parasite eggs. To date, 11 cases of human infection have been reported in the Netherlands, Argentina, Mexico, South Africa, Brazil, France, India and Vietnam (Table 1) [24-32], and animal infections have been detected in cattle, monkeys, camels, pigs,

Table 1 Summary of human cases of Echinococcus ortleppi

\begin{tabular}{|c|c|c|c|c|}
\hline Year & Country & No. of cases & Cyst localization & Reference \\
\hline 1988 & Netherlands & 1 & Spleen & Bowles et al. [24] \\
\hline 2002 & Argentina & 1 & Liver & Kamenetzky et al. [25] \\
\hline 2004 & Mexico & 1 & Liver & Maravilla et al. [26] \\
\hline 2010-2012 & South Africa & 1 & Liver & Mogoye et al. [27] \\
\hline 2011 & Brazil & 1 & - & de la Rue et al. [28] \\
\hline $2011-2012$ & France & 2 & Livers & Grenouillet et al. [29] \\
\hline 2013 & India & 1 & Liver & Sharma et al. [30] \\
\hline 2017 & Vietnam & 2 & Lungs & Van De \& Le Van [31] \\
\hline 2018 & France & 1 & Vertebral & Basmaciyan et al. [32] \\
\hline
\end{tabular}


cows, goats, sheep, oryx, bovines, crested porcupines and spotted deer in Asia (India, Vietnam, Egypt, Bhutan and Iran), Africa (Kenya, South Africa, Sudan, Ethiopia, Zambia and Namibia), South America (Brazil and Chile) and Europe (the UK, France and Italy) (Table 2) [3, 8-12, 24, 26, 33-42]. Human infection is rare, and it appears that human $E$. ortleppi infection is very uncommon and restricted to certain areas. Echinococcus ortleppi can cause high infection rates in cattle; in Brazil, the ratio of E. granulosus (G1) to E. ortleppi (G5) cysts in cattle is almost 1 to 1 [38].

China is one of the most important endemic regions of echinococcosis [43], and echinococcosis is a major parasitic problem in humans and livestock. It has been estimated that China has $0.6-1.3$ million cases of human echinococcosis by 2000 [44]. Most of the provinces have reported human infections, and western and northwest China are the main endemic areas.
The eastern Tibetan Plateau, China, has the highest reported prevalence of echinococcosis in the world [45]. Echinococcus granulosus and E. multilocularis are common species in China, and five genotypes of $E$. granulosus (s.l.), namely G1, G3, G6, G7 and G10, have been reported [14-18]. Here, we report a case of $E$. ortleppi (G5) infection in a human residing in a nonendemic echinococcosis area in China. It is generally believed that humans who are infected with echinococcosis in non-endemic areas obtained the infection mainly from endemic areas when they visited these areas or ingested the eggs on contaminated fruits from endemic areas. In this study, we did not detect hydatid infection in dog or human samples collected near the patient's home. Because the incubation period of echinococcosis can be as long as 30 years, it is impossible to determine whether the reported case should be considered an imported or local case.

Table 2 Summary of animal infection of Echinococcus ortleppi

\begin{tabular}{|c|c|c|c|c|}
\hline Year & Country & Species & No. infected & Reference \\
\hline \multicolumn{5}{|l|}{ Asia } \\
\hline 2009 & India & Cattle/buffalo/pig & $3 / 2 / 4$ & Pednekar et al. [8] \\
\hline 2009 & Vietnam & Monkey & 1 & Pednekar et al. [8] \\
\hline 2015 & Egypt & Camel & 1 & Amer et al. [11] \\
\hline 2016 & Bhutan & Cattle & 1 & Thapa et al. [33] \\
\hline 2017 & Iran & Camel & 1 & Ebrahimipour et al. [34] \\
\hline \multicolumn{5}{|l|}{ Africa } \\
\hline 2004 & Kenya & Cattle/pig & $2 / 1$ & Dinkel et al. [9] \\
\hline 2010-2012 & South Africa & Cow & 1 & Mogoye et al. [27] \\
\hline 2013 & Sudan & Camel & 1 & Ahmed et al. [35] \\
\hline 2013 & Kenya & Cattle/goat/sheep & $23 / 3 / 2$ & Mbaya et al. [10] \\
\hline 2015 & Ethiopia & Cattle/pig & $5 / 1$ & Tigre et al. [36] \\
\hline 2016 & Kenya & Cattle/goat/camel/sheep & $54 / 3 / 2 / 1$ & Addy et al. [3] \\
\hline 2016 & Zambia & Cattle/pig & $52 / 1$ & Addy et al. [3] \\
\hline 2016 & Namibia & Cattle/oryx & $35 / 3$ & Addy et al. [3] \\
\hline 2016 & Ethiopia & Cattle & 7 & Addy et al. [3] \\
\hline 2016 & Sudan & Cattle/camel & $15 / 1$ & Addy et al. [3] \\
\hline 2018 & Kenya & Dog & 1 & Mulinge et al. [37] \\
\hline \multicolumn{5}{|l|}{ America } \\
\hline 2002 & Argentina & Cattle/dog & $5 / 2$ & Kamenetzky et al. [25] \\
\hline 2012 & Brazil & Cattle & 277 & Balbinotti et al. [38] \\
\hline 2016 & Brazil & Cattle & 7 & Addy et al. [3] \\
\hline 2016 & Brazil & Bovine & 250 & Monteiro et al. [39] \\
\hline 2018 & Brazil & Crested porcupine & 1 & Hodzic et al. [40] \\
\hline 2018 & Chile & Cattle & 2 & Correa et al. [41] \\
\hline \multicolumn{5}{|l|}{ Europe } \\
\hline 2012 & UK & Spotted deer & 1 & Boufana et al. [12] \\
\hline 2014 & France & Cattle & 7 & Grenouillet et al. [29] \\
\hline 2016 & France & Cattle & 7 & Addy et al. [3] \\
\hline 2008 & Italy & Cattle & 1 & Casulli et al. [42] \\
\hline
\end{tabular}


Three confirmed human cases of hydatid infections in Guangxi have been reported, and the patients did not reside in echinococcosis-endemic areas. Because the parasites were not subjected to molecular analysis, their species and genotype were not identified. Some echinococcosis cases in non-endemic areas of China have been reported, and the infection source in some of these cases has not been identified. We hypothesize that these patients might also have been considered cases of local E. ortleppi infection. Therefore, we strongly suggest that the parasites from patients with echinococcosis residing in non-endemic areas should be subjected to genotyping and molecular analysis to identify the Echinococcus species.

\section{Conclusions}

This study reports a case of E. ortleppi infection that caused cystic echinococcosis in the liver of a Chinese patient. To our knowledge, this case constitutes the first detection of this species in China, and the identification of this first case highlights the need to enhance national surveillance efforts, particularly human, livestock and dog surveillance in non-endemic areas. Moreover, the Echinococcus species and genotype of infections should be detected.

\section{Additional files}

Additional file 1: Figure S1. Phylogenetic tree for Echinococcus spp. based on the cox 1 gene including the sequence of E. ortleppi from China.

Additional file 2: Figure S2. Phylogenetic tree for Echinococcus spp. based on the nad 1 gene including the sequence of E. ortleppi from China.

\section{Abbreviations}

cox1: cytochrome c oxidase subunit 1; nad1: dehydrogenase subunit 1 .

\section{Acknowledgements}

We sincerely thank Chengwei Meng from the Rongshui County Center for Disease Prevention and Control for collecting the data described in this study.

\section{Authors' contributions}

YLS and YCY developed the study protocol. YLS, XLW, ZYW, JL, JZH and YCY performed the fieldwork and contributed to the data analysis. YLS and YCY performed the final analysis. YLS wrote the first version of the manuscript. All authors read and approved the final manuscript.

\section{Funding}

This research was supported by the National Public Welfare Scientific Research Project (no. 201502021).

\section{Availability of data and materials}

The data used in this study are available upon request from the corresponding author.

\section{Ethics approval and consent to participate}

The study was approved by the Guangxi Zhuang Autonomous Region Center for Disease Control and Prevention Ethics Committee. All medical procedures were performed with the patient's approval. The research aim, methods, risks and benefits of the study were explained in detail to the patient. Liver pus was collected at the People's Hospital of Miao Autonomous County, Rongshui County, and sent to the Parasitic Disease Prevention and Control Institute of the Guangxi Center for Disease Control for diagnosis.

\section{Consent for publication}

Not applicable.

\section{Competing interests}

The authors declare that they have no competing interests.

\section{Author details}

${ }^{1}$ Institute of Parasitic Disease Prevention and Control, Guangxi Zhuang Autonomous Region Center for Disease Control and Prevention, Nanning 530028,

China. ${ }^{2}$ School of Public Health, Guangxi Medical University, Nanning 530021, China.

Received: 17 January 2019 Accepted: 1 August 2019

Published online: 09 August 2019

\section{References}

1. De NV, Khue PV. Zoonotic parasites. Scientific book. Vietnam: Education Published House; 2009. p. 116-7.

2. De NV, Le TH. Taeniasis/cysticercosis and molecular amplication. Wuhan: Scientific Book Medical Published House; 2010.

3. Addy F, Wassermann M, Banda F, Mbaya H, Aschenborn J, Aschenborn O, et al. Genetic polymorphism and population structure of Echinococcus ortleppi. Parasitology. 2017;144:450-8.

4. Nakao M, Lavikainen A, Yanagida T, Ito A. Phylogenetic systematics of the genus Echinococcus (Cestoda: Taeniidae). Int J Parasitol. 2013;43:1017-29.

5. Saarma U, Jogisalu I, Moks E, Varcasia A, Lavikainen A, Oksanen A, et al. A novel phylogeny for the genus Echinococcus, based on nuclear data, challenges relationships based on mitochondrial evidence. Parasitology. 2009;136:317-28.

6. Thompson RC, McManus DP. Towards a taxonomic revision of the genus Echinococcus. Trends Parasitol. 2002;18:452-7.

7. Romig T, Ebi D, Wassermann M. Taxonomy and molecular epidemiology of Echinococcus granulosus sensu lato. Vet Parasitol. 2015:213:76-84.

8. Pednekar RP, Gatne ML, Thompson RC, Traub RJ. Molecular and morphological characterisation of Echinococcus from food producing animals in India. Vet Parasitol. 2009;165:58-65.

9. Dinkel A, Njoroge EM, Zimmermann A, Walz M, Zeyhle E, Elmahdi IE, et al. A PCR system for detection of species and genotypes of the Echinococcus granulosus-complex, with reference to the epidemiological situation in eastern Africa. Int J Parasitol. 2004;34:645-53.

10. Mbaya H, Magambo J, Njenga S, Zeyhle E, Mbae C, Mulinge E, et al. Echinococcus spp. in Central Kenya: a different story. Parasitol Res. 2014;113:3789-94.

11. Amer S, Helal IB, Kamau E, Feng Y, Xiao L. Molecular characterization of Echinococcus granulosus sensu lato from farm animals in Egypt. PLOS ONE. 2015:10:e0118509.

12. Boufana B, Stidworthy MF, Bell S, Chantrey J, Masters N, Unwin S, et al. Echinococcus and Taenia spp. from captive mammals in the United Kingdom. Vet Parasitol. 2012;190:95-103.

13. Rojas CAA, Romig T, Lightowlers MW. Echinococcus granulosus sensu lato genotypes infecting humans - review of current knowledge. Int J Parasitol. 2014:44:9-18.

14. Yang YR, Rosenzvit MC, Zhang LH, Zhang JZ, McManus DP. Molecular study of Echinococcus in West-Central China. Parasitology. 2005:131:547-55.

15. Bart JM, Abdukader M, Zhang YL, Lin RY, Wang YH, Nakao M, et al. Genotyping of human cystic Echinococcosis in Xinjiang, PR China. Parasitology. 2006;133:571-9.

16. Zhang YL, Bart JM, Wen H, Ma XD, Miao YQ, Lin RY, et al. Molecular evidence of sheep (G1) and camel (G6) strains of Echinococcus granulosus in Xinjiang, China. Chin J Parasit Dis Con. 2005;18:333-5.

17. Zhang T, Yang D, Zeng Z, Zhao W, Liu A, Piao D, et al. Genetic characterization of human-derived hydatid cysts of Echinococcus granulosus sensu 
lato in Heilongjiang Province and the first report of $\mathrm{G} 7$ genotype of $E$. canadensis in humans in China. PLoS ONE. 2014;9:e109059.

18. Yang D, Zhang T, Zeng Z, Zhao W, Zhang W, Liu A. The first report of human-derived G10 genotype of Echinococcus canadensis in China and possible sources and routes of transmission. Parasitol Int. 2015;64:330-3.

19. Xiao N, Qiu J, Nakao M, Li T, Yang W, Chen X, et al. Echinococcus shiquicus n. sp., a taeniid cestode from Tibetan fox and plateau pika in China. Int J Parasitol. 2005;35:693-701.

20. Yang JK, Jia WZ, Jing T, Tian GF, Cheng XH. Analysis of genetic variation of Echinococcus granulosus collected from three provinces in China. Vet Sci China. 2004;34:12-6.

21. Bowles J, McManus DP. NADH dehydrogenase 1 gene sequences compared for species and strains of the genus Echinococcus. Int J Parasitol. 1993;23:969-72

22. Kumar S, Stecher G, Tamura K. MEGA7: molecular evolutionary genetics analysis version 7.0 for bigger datasets. Mol Biol Evol. 2016;33:1870-4.

23. WHO Informal Working Group. International classification of ultrasound images in cystic echinococcosis for application in clinical and field epidemiological settings. Acta Trop. 2003;85:253-61.

24. Bowles J, van Knapen F, McManus D. Cattle strain of Echinococcus granulosus and human infection. Lancet. 1992;339:1358.

25. Kamenetzky L, Gutierrez AM, Canova SG, Haag KL, Guarnera EA, Parra A, et al. Several strains of Echinococcus granulosus infect livestock and humans in Argentina. Infect Genet Evol. 2002:2:129-36.

26. Maravilla P, Andrew Thompson RC, Palacios-Ruiz JA, Estcourt A, RamirezSolis E, Mondragon-de-la-Pena C, et al. Echinococcus granulosus cattle strain identification in an autochthonous case of cystic Echinococcosis in Central Mexico. Acta Trop. 2004;92:231-6.

27. Mogoye BK, Menezes CN, Wong ML, Stacey S, von Delft D, Wahlers K, et al. First insights into species and genotypes of Echinococcus in South Africa. Vet Parasitol. 2013:196:427-32.

28. de la Rue ML, Takano K, Brochado JF, Costa CV, Soares AG, Yamano K, et al. Infection of humans and animals with Echinococcus granulosus (G1 and G3 strains) and E. ortleppi in southern Brazil. Vet Parasitol. 2011;177:97-103.

29. Grenouillet F, Umhang G, Arbez-Gindre F, Mantion G, Delabrousse E, MilIon L, et al. Echinococcus ortleppi infections in humans and cattle, France. Emerg Infect Dis. 2014;20:2100-2.

30. Sharma M, Sehgal R, Fomda BA, Malhotra A, Malla N. Molecular characterization of Echinococcus granulosus cysts in north Indian patients: identification of G1, G3, G5 and G6 genotypes. PLoS Negl Trop Dis. 2013:7:e2262

31. Van De N, Le Van D. The first report of two cases of cystic echinococcosis in the lung by Echinococcus ortleppi infection, in Vietnam. Res Rep Trop Med. 2017:8:45-51.

32. Basmaciyan L, Burlet B, Ramla S, Blot M, Mahy S, Aubriot-Lorton MH, et al. First case of human primary vertebral cystic Echinococcosis due to Echinococcus ortleppi. J Clin Med. 2018;7:E443.
33. Thapa NK, Armua-Fernandez MT, Kinzang D, Gurung RB, Wangdi P, Deplazes P. Detection of Echinococcus granulosus and Echinococcus ortleppi in Bhutan. Parasitol Int. 2017:66:139-41.

34. Ebrahimipour M, Sadjjadi SM, Darani HY, Najjari M. Molecular studies on cystic Echinococcosis of camel (Camelus dromedarius) and report of Echinococcus ortleppi in Iran. Iran J Parasitol. 2017;12:323-31.

35. Ahmed ME, Eltom KH, Musa NO, Ali IA, Elamin FM, Grobusch MP, et al. First report on circulation of Echinococcus ortleppi in the one humped camel (Camelus dromedaries), Sudan. BMC Vet Res. 2013;9:127.

36. Tigre W, Deresa B, Haile A, Gabriel S, Victor B, Pelt JV, et al. Molecular characterization of Echinococcus granulosus s.l. cysts from cattle, camels, goats and pigs in Ethiopia. Vet Parasitol. 2016;215:17-21.

37. Mulinge E, Magambo J, Odongo D, Njenga S, Zeyhle E, Mbae C, et al. Molecular characterization of Echinococcus species in dogs from four regions of Kenya. Vet Parasitol. 2018;255:49-57.

38. Balbinotti H, Santos GB, Badaraco J, Arend AC, Graichen DA, Haag KL, et al. Echinococcus ortleppi (G5) and Echinococcus granulosus sensu stricto (G1) loads in cattle from southern Brazil. Vet Parasitol. 2012;188:255-60.

39. Monteiro DU, de Azevedo MI, Weiblen C, Ribeiro TC, Emmanouilidis J, Tonin AA, et al. Echinococcus granulosus sensu stricto, Echinococcus canadensis (G7), and Echinococcus ortleppi in fertile hydatid cysts isolated from cattle in Southern Brazil. Acta Trop. 2016;164:41-4.

40. Hodzic A, Alic A, Supic J, Skapur V, Duscher GG. Echinococcus ortleppi, the cattle strain in a crested porcupine (Hystrix cristata): a new host record. Vet Parasitol. 2018;256:32-4.

41. Correa F, Stoore C, Horlacher P, Jimenez M, Hidalgo C, Rojas CAA, et al. First description of Echinococcus ortleppi and cystic echinococcosis infection status in Chile. PLoS One. 2018;13:e0197620.

42. Casulli A, Manfredi MT, La Rosa G, Cerbo AR, Genchi C, Pozio E. Echinococcus ortleppi and E. granulosus G1, G2 and G3 genotypes in Italian bovines. Vet Parasitol. 2008:155:168-72.

43. Eckert J, Schantz PM, Gasser RB, Torgerson PR, Bessonov AS, Movsessian SO, et al. Geographic distribution and prevalence. In: Eckert J, Gemmell MA, Meslin FX, Pawlowski ZS, editors. WHO/OIE manual on Echinococcosis in humans and animals: a public health problem of global concern. Geneva: World Health Organisation; 2001. p. 100-42.

44. Ito A, Urbani C, Qiu J, Vuitton DA, Qiu D, Henth DD, et al. Control of echinococcosis and cysticercosis: a public health challenge to international cooperation in China. Acta Trop. 2003;86:3-17.

45. Li L, Xiao Q, Fu DR, Xiao T, Duan MX, Xie F, et al. Epidemiology of Echinococcosis in village populations in Ningxia Hui autonomous region. Chin J Zoon. 2005;21:359-60.

\section{Publisher's Note}

Springer Nature remains neutral with regard to jurisdictional claims in published maps and institutional affiliations.

Ready to submit your research? Choose BMC and benefit from:

- fast, convenient online submission

- thorough peer review by experienced researchers in your field

- rapid publication on acceptance

- support for research data, including large and complex data types

- gold Open Access which fosters wider collaboration and increased citations

- maximum visibility for your research: over $100 \mathrm{M}$ website views per year

At $\mathrm{BMC}$, research is always in progress.

Learn more biomedcentral.com/submissions 